\title{
Microfluorometer Assay to Measure the Expression of $\beta$-Galactosidase and Green Fluorescent Protein Reporter Genes in Single Drosophila Flies
}

\author{
BioTechniques 30:594-601 (March 2001)
}

\section{A.C. Jung, M.-C. Criqui, S. Rutschmann, J.A. Hoffmann, and D. Ferrandon \\ Centre National de la Recherche Scientifique, Strasbourg, France}

\section{INTRODUCTION}

The Human Genome Sequencing Project is now well underway and is leading to the identification of scores of previously unknown genes $(9,17)$. One of the major challenges will be to understand the function of these new genes. One approach to solve this problem is to investigate the function of homologous genes in genetically tractable model organisms such as Caenorhabditis elegans or Drosophila melanogaster (19). Indeed, the genome sequence of these two organisms is now available $(1,27)$. The detailed analysis of several hundred genes in these organisms has already been performed. However, these genes are often analyzed more qualitatively than quantitatively (e.g., genes that control development) $(14,20)$. For instance, novel developmental genes have been identified with an enhancer-trap strategy according to their histochemical expression patterns using the bacterial LacZ gene that encodes $\beta$-galactosidase as a reporter of gene expression $(3,28)$. It is likely that some genes would be more adequately studied using quantitative methods, for instance, genes involved in regulating growth control (29). In this respect, reporter genes will be especially useful to study easily the expression levels of target genes in different conditions, whether genetic or environmental. Some quantitative techniques to monitor gene expression using $\beta$-galactosidase or chloramphenicol acetyltransferase reporter genes have been reported in Dro- sophila (2). However, these techniques are relatively cumbersome to apply and require the preparation of bulk fly extracts. In this paper, we report a technique based on two reporter genes, $\beta$ galactosidase and green fluorescent protein $(G F P)$, that allows the semiquantitative monitoring of the expression levels of two genes induced during immune response in single $D$. melanogaster flies.

The Drosophila innate host defense relies on the synthesis of potent antibacterial or antifungal peptides in response to microbial infection $(11,12)$. Interestingly, flies mutant for the $\mathrm{im}$ mune deficiency (imd) gene synthesize only reduced amounts of Diptericin and other antibacterial peptides and are sensitive to bacterial infections (15), whereas mutants of the Toll pathway, such as flies mutated in the Dorsal-related immunity factor (Dif) gene are unable to express the antifungal peptide Drosomycin and are susceptible to fungal infections $(16,23)$. Our goal was to systematically identify all the genes required for the regulation of the Drosophila humoral immune response using ethylmethane sulfonate (EMS) saturation mutagenesis. To screen the mutated Drosophila lines, we used transgenic flies expressing the $L a c Z$ gene encoding $\beta$-galactosidase under the control of the Diptericin promoter and GFP under the control of the Drosomycin promoter (both transgenes are carried on the $\mathrm{X}$ chromosome). The expression of the reporter genes in these 
strains has been shown to mimic that of the endogenous peptides $(10,21)$. Here, we describe a powerful assay that turned out to be invaluable in processing a large number of mutated lines and in isolating new mutants of the Drosophila immune response.

\section{MATERIAL AND METHODS}

\section{Fly Strains}

Fly cultures and crosses were grown on standard fly medium at $25^{\circ} \mathrm{C} . y w$ DD1 flies carry both $P\left[w^{+} m C\right.$ Dipt:: LacZ $=$ pDipt-LacZ $]$ and $P\left[w^{+} m C\right.$ Drom: $G F P=$ pDrom-GFP S65T] reporter transgenes $(10,21)$. We used both $y w D D 1 ; D T S 91 / C y O$ and $y w D D 1 ; c n$ $b w / c n b w$ flies as wild-type controls. No significant difference in the induction of the transgenes could be observed between these two strains. The DTS91 chromosome is described in Reference 20. Mutants in the imd gene exhibit an impaired activation of the Diptericin gene (15). Mutants in the Dif gene are characterized by a low inducibility of the Drosomycin (23). Or ${ }^{\mathrm{R}}$ is a wild-type reference strain.

\section{Immune Response Induction}

Bacterial challenge was performed by pricking flies with a tungsten needle previously dipped into a concentrated culture of E. coli 1106 and Micrococcus luteus (CIP:A270).

\section{Detection of Reporter Gene Expression}

After septic injury, flies were incubated at $20^{\circ} \mathrm{C}$ in vials for $36 \mathrm{~h}$ before being frozen in microplates. Alternatively, in a quicker procedure used during the screens, flies were directly introduced after immunization in single wells of a black 96-well microplate kept on ice (96-well black Cliniplates ${ }^{\text {TM}}$; Labsystems, Helsinki, Finland). (White plates had also been tested: a stronger fluorescent signal was detected, but the background became unacceptably high). A 3- $\mu \mathrm{L}$ drop of a $1 \%$ sucrose solution was then added in each well to allow the survival of immunized insects in the microplate. The plates were covered with lids for thermowell plates (Costar, Brumath, France) and left at $20^{\circ} \mathrm{C}$ to allow the flies to develop their immune response. Thirty-six hours after induction, the plates were frozen at $-20^{\circ} \mathrm{C}$. For analysis, flies were crushed with a Multiple Homogenizer Type BA/MH96 (Burkard Scientific, Uxbridge, UK) in $50 \mu \mathrm{L} 10 \mathrm{mM}$ Tris (pH 8.4), $100 \mathrm{mM}$ $\mathrm{NaCl}, 1 \mathrm{mM} \mathrm{MgCl} 2,10 \mathrm{mM}$ dithiothreitol (homogenizing buffer described in Reference 6). The final volume was adjusted to $100 \mu \mathrm{L}$ with homogenizing buffer. The plate was then analyzed with a Fluoroskan Ascent ${ }^{\circledR}$ microfluorometer type 374 (Labsystems). The plates were first shaken (time: $30 \mathrm{~s}$; diameter: 25 $\mathrm{mm}$; speed: 120), and the fluorescence of transgenic GFP-S65T was measured [excitation filter: $485 \mathrm{~nm}$; emission filter: $520 \mathrm{~nm}$; moving type: 3 ; plate acceleration: 10; integration time: $20 \mathrm{~ms}$ (varying the integration time between 1 $\mathrm{ms}$ and $1 \mathrm{~s}$ did not make a significant difference)]. In initial experiments and for the screens, a less sensitive emission filter $(510 \mathrm{~nm})$ was used. In this case, the GFP reporter was not accurately detected in males. We then obtained better results using males that carried two copies of the GFP transgene (unpublished data). The results were processed with the Fluoroskan Ascent software (Labsystems) and given in arbitrary units for each single fly. To measure the expression of the pDipt-LacZ transgene, $10 \mu \mathrm{L}$ of a $20 \mathrm{mM} 4$ methyl umbelliferyl- $\beta$ D galactopyranoside (MUG) (Sigma, St. Quentin Fallaviers, France) in dimethyl sulfoxide (DMSO) were then added in each well by the machine (dispenser 1; moving type: 3 ; plate acceleration: 10 ; dispenser speed: 18). MUG is a nonfluorescent $\beta$-galactosidase substrate that produces, after enzymatic cleavage, methyl umbelliferone (MU), a fluorescent molecule. The plates were shaken again after addition of the MUG solution (time: $30 \mathrm{~s}$; diameter: $25 \mathrm{~mm}$; speed: 120), and the kinetics of appearance of MU was monitored in each well every $25 \mathrm{~s}$ for a total of 15 measures (excitation filter: $355 \mathrm{~nm}$; emission filter: 460 nm; moving type: 3 ; plate acceleration: 10; integration time: $20 \mathrm{~ms}$ ). The software plotted the results as a graph and was also able to determine the maximum slope of the curve, thus providing a quantitative estimate of $\beta$-galactosi- 
dase activity in the wells. It usually takes 10-15 min to process a plate. We routinely prepare the next microplate while the machine is reading another plate.

Northern blot analysis was carried out as previously described (23).

\section{RESULTS AND DISCUSSION}

\section{Detection of the $\beta$-galactosidase Reporter Gene Activity}

The kinetics of appearance of the fluorescent cleavage product of the $\beta$ galactosidase substrate MUG was monitored to estimate the activity of the pDipt-LacZ transgene in single flies (see Materials and Methods) as shown in Figure 1 and Table 1. The fluorescent product accumulates in immune-challenged wild-type females (boxes A1A6) and males (boxes C1-C6), but not in control noninjured flies (B1-B6 and D1-D6) or in wells with buffer only (E1-E6 and F1-F6). The fluorescence observed in induced insects is usually

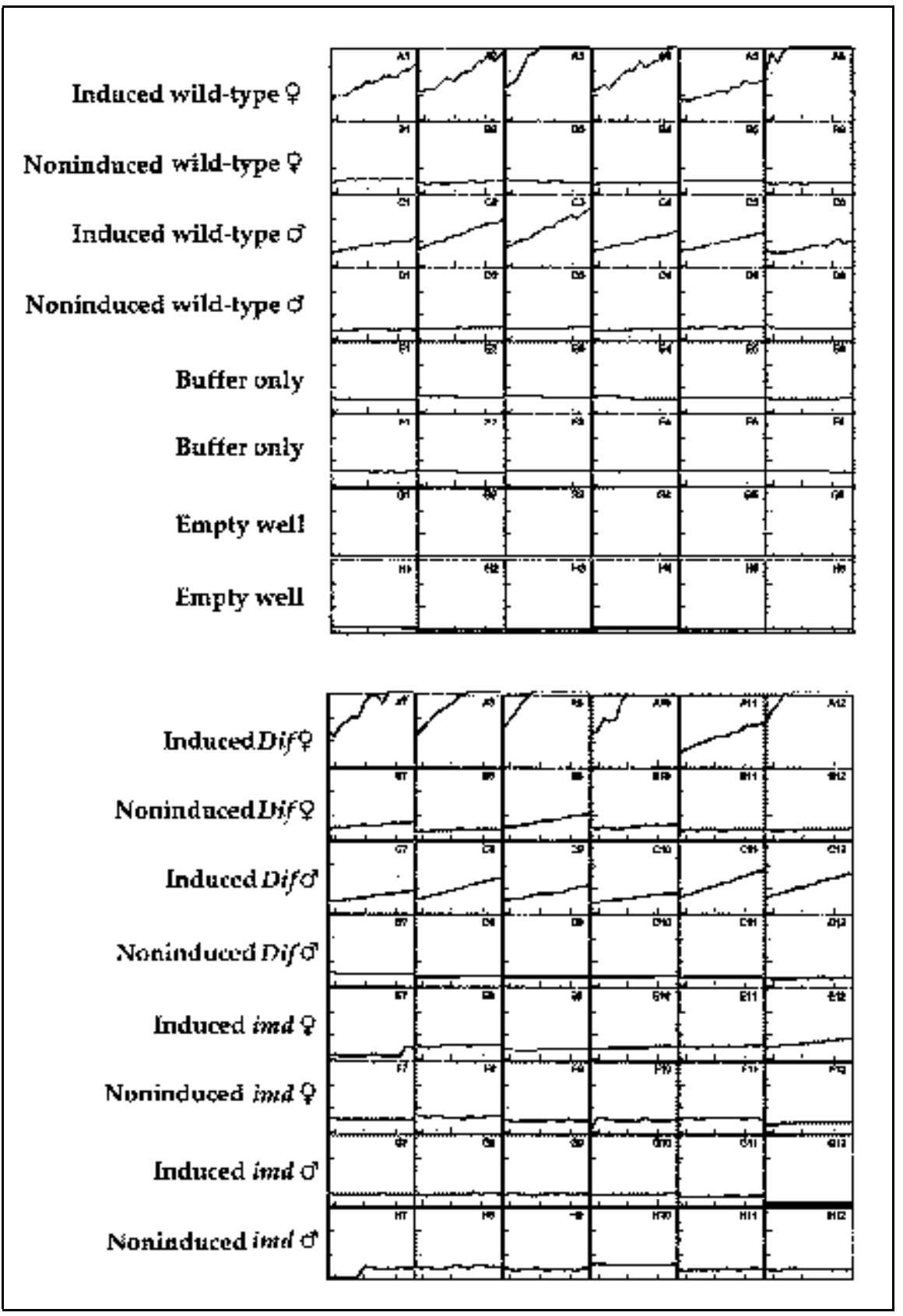

Figure 1. Detection of the pDipt-LacZ transgene expression in single adult flies. Immunized and nonimmunized flies were put in single wells of the microplate before processing, as described in Materials and Methods. Each box in the figure corresponds to a well, its number indicated at the top right corner of the box. The curve in each box corresponds to the kinetics of appearance of a fluorescent product generated by $\beta$ galactosidase enzymatic activity. The machine gives measurements in arbitrary units in the 0-6000 range ( $\mathrm{Y}$-axis). To get a better resolution, especially with males, we usually limited the values of the Y-axis to 600-1200. Note that induced females easily attain this value and often saturate the detector by reaching values over 6000 (e.g., boxes A3 and A6). X-axis: time ; the kinetics was stopped after 15 measurements (i.e., around $6 \mathrm{~min})$. Boxes A1-A6; B1-B6 : y w $D D 1 ; c n b w / c n$ bwfemales (used as wild-type controls). Boxes C1-C6; D1-D6: y w DD1;cn bw/cn bwmales. Boxes E1-E6; F1-F6: only homogenizing buffer was added to these wells. Boxes G1-G6; H1-H6: empty wells. Boxes A7-A12; B7-B12: Dif mutant females. Boxes C7-C12; D7-D12: Dif mutant males. Boxes E7-E12; F7-F12: imd mutant females. Boxes G7-G12; H7-H12: imd mutant males. 
Table 1. Detection of the pDipt-LacZ Transgene Expression in Single Adult Flies

\begin{tabular}{|c|c|c|c|c|c|c|c|c|}
\hline & & T" & 2 & 3 & 4 & Ts & 5 & Mean valus \\
\hline A & Induced wildubye & 256.2 & 330.8 & 458.6 & 494.5 & 217.7 & 1055.2 & 356.5 \\
\hline $\bar{B}$ & Nouludated wild-lype & 50.2 & 53.8 & -47.5 & 28.1 & $-20 \div 0$ & 30.3 & 28.7 \\
\hline $\mathbf{C}$ & Induced wild-type $\bar{c}^{2}$ & 115.6 & 1457.1 & $30 ! 3$ & 1296 & 113.8 & $26 \hat{2} 8$ & 186.2 \\
\hline $\bar{D}$ & Norind hecel wild-1 $y$ pe o & 27.7 & 21.8 & 18.8 & 27.3 & 49.3 & -18.2 & 24.1 \\
\hline $\bar{E}$ & 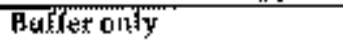 & -3.5 & $-2+3.50$ & -37.1 & -4.5 .45 & 9.17 & -6.0 & 7.5 \\
\hline$\underline{F}$ & Buffer un? & -4.5 & -9.3 & -9.1 & -12.1 & $-14 . \underline{-1}$ & -13.7 & 0 \\
\hline$G$ & Empty we耳l & -1.2 & -6.6 & -0.8 & 0.6 & $-1,2$ & 0.5 & 0.2 \\
\hline H & Empty weti & -4.7 & $-1) . \%$ & $\{1 . .7$ & 1.1 & -6.5 & 0.5 & 02 \\
\hline
\end{tabular}

\begin{tabular}{|c|c|c|c|c|c|c|c|c|}
\hline & & 7 & 8 & 9 & T10 & T1T & 12 & Meart Value \\
\hline A & flduced Ihit 7 & M & 497.4 & $72+41$ & 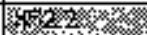 & 77 ti.. & 60.1 .7 & 328.5 \\
\hline B & Nonindured Dif & 84.1 & 35.5 & 93.5 & 66.5 & 20.0 & 35,9 & 55.9 \\
\hline 5 & Enduced Mific & 5.:5 & 47,3 & 1.7หxis.5 & $4 ! 3.2$ & 1,3.3.4 & 1적.․ & 100.4 \\
\hline D & Koninduced [Jif $0^{\prime}$ & -8.8 & 19.6 & 6.2 & 14.5 & 12.7 & 23.6 & 12.6 \\
\hline$\overline{\mathbf{F}}$ & Endtuced inud & Fy & fill. & 411.7 & 23.2 & 57.5 & 62.1 & 40.5 \\
\hline I & Noninduced imd & .22 .8 & .340 & -30.9 & 5 & $-8 B .6$ & 63.3 & 19.4 \\
\hline Si & Indeleed inid d & $-22,1$ & 50.1 & 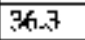 & 4.7 & 701.9 & f. 移 & 24.7 \\
\hline II & Vaninduced imd $\varphi^{\prime}$ & $3 G B=$ & .34 .7 & 44.4 & $\therefore 1 . R$ & 35.5 & $-44 .\{1$ & 5.9 \\
\hline
\end{tabular}

The level of induced expression of the pDipt-LacZ reporter transgene was measured in the same flies as those described in Figure 1. To this end, the program automatically determined the maximum slope of each curve using the three optimal consecutive points in the kinetics. A mean value of the six measures for each type of flies is given. However, these maximum slope values should be used with caution. Indeed, when the curve is irregular [e.g., A7 vs. A8 in Figure 1 (fly debris in the optical path?)] or when the slope is weak (D7 - H12; note especially E7 and H7), the values can be misleading. The shaded values were not taken into account for mean calculations. Negative values were counted as 0 . The differences observed between induced and noninduced wild-type males and females are statistically significant [Student's $t$ test with $P>0.01$ (females) and $P>0.001$ (males)].

Table 2. Detection of the pDrom-GFP Transgene Expression in Single Adult Flies

\begin{tabular}{|c|c|c|c|c|c|c|c|c|}
\hline & & T" & $T^{2}$ & 3 & 4 & $T 2$ & 6 & Mean value \\
\hline $\mathbf{A}$ & Indudud wld-type & 229.1 & E6.7 & 16.2 & $2 \overline{5} 4.7$ & $7 ! .6$ & 171.4 & 713,3 \\
\hline $\mathrm{b}$ & \begin{tabular}{|l} 
Naninduced wild-type $\$$ \\
\end{tabular} & 24.5 & 23.6 & 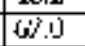 & 4.2 & 13.6 & 9.1 & 24.4 \\
\hline $\mathrm{C}$ & Induced walld-type of & 40.1 & 61.6 & 37.1 & 37.9 & 13.5 & 鱿 & 45.0 \\
\hline $\mathrm{U}$ & Neninduced wildtype $\theta$ & $\dot{9}$ & E.5 & 5.5 & 1.5 & 9.8 & $3.7^{n}$ & 7.1 \\
\hline $\mathrm{E}$ & Buffet onl & -1.6 & -1.1 & -0.8 & -1.7 & $-1-3$ & -0.9 & -3]$. \\
\hline$i^{z}$ & Uuffer onls & -2.7 & -2.6 & 2.8 & .50 & 2.3 & -1.5 & -2.5 \\
\hline $\mathrm{C}$ & Empty well & 5.1 & 6.2 & $\overline{5.4}$ & 6.5 & 5.7 & 6.1 & 5.8 \\
\hline H & kmply well & 5.3 & س & 3.4 & 4.9 & 5.7 & 5.3 & 5.0 \\
\hline & & 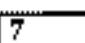 & 8 & {$[9$} & TT3 & III & 12 & Mean Value \\
\hline $\mathbf{A}$ & Induced Dif & 54.4 & 27.7 & 125.6 & 45.6 & 58.7 & 45.2 & 60.0 \\
\hline $\bar{B}$ & Noninduced Dif & 69.6 & 62,5 & 21.7 & atdit & 17.8 & 23.4 & 40. \\
\hline$c$ & Índuced Difo' & $16 . \hat{3}$ & 32.7 & 13.5 & $18 . B^{3}$ & 16.5 & $\{6.5$ & 18.9 \\
\hline "D" & Nonieduled in for & -1.7 & 5.1 & 8.1 & 11.4 & 4.2 & 5.13 & 5.4 \\
\hline $\mathbf{E}$ & Lnduced imd 9 & 337.1 & 199.1 & 148.6 & 340.0 & 312.7 & 231.7 & 263.5 \\
\hline $\mathbf{F}$ & Nonīuduced itrd 8 & 306 & 20.3 & 89.7 & 26.7 & $24 . \dot{0}$ & 63.1 & 42.6 \\
\hline $\mathrm{G}$ & Indtoed ind o & 1003.9 & 75.4 & 41.3 & 6 & 101.0 & z̧2.1 & 78.4 \\
\hline I1 & Noninduced ind o & $1: 1.4$ & $10 . i]$ & t.i & 13.8 & 0.3 & 3,8 & 8.9 \\
\hline
\end{tabular}

The level of induced expression of the pDrom-GFPreporter transgene was measured in the same flies as those described in Figure 1. The GFP fluorescence is expressed in arbitrary units. A mean value of the six measures for each type of flies is given. 
to that observed in noninduced wildtype (B1-B6; D1-D6) or noninduced imd flies (F7-F12; H7-H12).

Dif mutant display a wild-type expression of the endogenous Diptericin gene (23). Accordingly, the $\beta$-galactosidase activity observed in Dif-induced females and males (A7-A12 and C7-C12) was comparable to that of the wild-type controls.

Similar results were obtained by monitoring the expression levels of endogenous Diptericin RNA by Northern blot analysis on total RNA isolated from bulk extracts of 20 females (Figure 2). We conclude that the data obtained with the pDipt-LacZ transgene using the microplate assay correctly reflected the expression of the Diptericin gene.

\section{Detection of GFP Reporter Gene Expression}

The fluorescence of GFP was measured to estimate the activity of the pDrom-GFP transgene in single flies (see Materials and methods) as shown in Table 2. Wild-type induced females are characterized by a GFP fluorescence value usually sixfold higher than that of noninduced females. Induced males display weaker fluorescence values than induced females, a sex difference in keeping with the results obtained with the pDipt-LacZ reporter gene (see above). However, the difference between induced and noninduced males was also in the sixfold range. The observed differences were statistically significant (Student's $t$ test with $\mathrm{P}<0.01$ ).

We were able with that approach to identify strains mutant for the inducibility of GFP. Dif mutants are characterized by a low inducibility of the expression of the Drosomycin gene (23). The results illustrated in Table 2 show that the GFP values of induced Dif males and females range roughly in the same interval as noninduced wildtype and Dif flies. On the contrary, imd mutant flies, in which endogenous Drosomycin inducibility is not impaired (16), exhibit GFP values comparable to those obtained in wild-type controls.

As for the pDipt-LacZ reporter gene, an important individual variability was observed for the expression of the GFP reporter gene. For example, the fluorescence intensity is between 46 and 254 in wild-type induced females (Table 2, boxes A1-A7). It is therefore advisable to test a high enough number of flies to get clear results; we routinely tried to test five to six females.

After immune challenge, endogenous Drosomycin RNA accumulates to high levels for at least $72 \mathrm{~h}$. The fluorescence of the $p$ Drom-GFP reporter gene becomes detectable in our system 12-15 $\mathrm{h}$ after induction, but the induced/noninduced signal ratio is low. Better reproducibility of induced/noninduced ratio was obtained after at least $36 \mathrm{~h}$ after induction (best: $72 \mathrm{~h}$ ). This time point is still compatible with the detection of the pDipt-LacZ reporter gene activation in adult flies. The transcriptional level of Diptericin gene peaks 12-24 h after septic injury, and transcription is still observed after $48 \mathrm{~h}$ (23). The activity of $\beta$ galactosidase is still easily detected $36 \mathrm{~h}$ after induction since this enzyme is rather stable in fly cells. For those reasons, we attained a reasonable compromise between the sensitivity of the two reporters by testing the flies $36 \mathrm{~h}$ after immune challenge.

As in the case of the pDipt-LacZ reporter gene, Northern blot analysis confirmed that the measurement of the pDrom-GFP transgene expression in the microplate assay accurately reports the endogenous Drosomycin RNA expression levels (Figure 2).

\section{CONCLUSIONS}

Many large-scale assays have been described to detect the expression of reporter genes in various organisms. The sequencing of the yeast Saccharomyces cerevisiae genome has spawned many such assays: for example, the identification of markers by random polypeptides fusions with GFP (25), the study of the regulation of gene expression on a genomic scale by DNA microarrays $(8,26)$, and large-scale genome analysis by transposon tagging and gene disruption (22).

The realization that many of the components of biological processes, and the way they interact with each other, will be conserved between flies and humans (19) will certainly lead to increased requirements for high-throughput assays to allow the functional analysis of the Drosophila genome that has become recently available. Here, we have described a quick microfluorometer assay to detect the activity of two reporter transgenes. We have used this assay in a large-scale mutagenesis screen to isolate mutations affecting the inducibility of two antimicrobial genes in adult flies after immune challenge: Diptericin and Drosomycin. In this process, about 8000 homozygous viable EMS mutant lines have been generated and screened, allowing the identifica-
Oh 6 h 48 a on fh 0 h th $48 \mathrm{~h}$

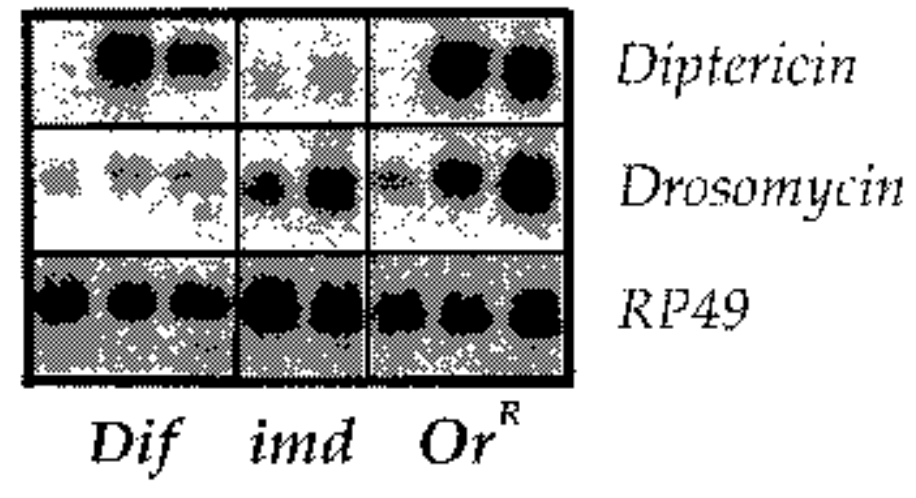

Figure 2. Expression of endogenous Diptericin and Drosomycin in wild-type and mutant backgrounds. A Northern blot was probed successively with Diptericin, Drosomycin, and Ribosomal Protein 49 (RP49) probes. RP49 RNA levels serve as loading controls. The time of incubation after infection is shown on top, and the phenotypes of the immunized flies are indicated at the bottom. $\operatorname{Or}^{\mathrm{R}}$ was used as a wild-type control strain in this experiment. 
tion of about 20 new mutations that represent several novel genes that control the humoral immune response (unpublished data) $(23,24)$. We expect that this microplate assay can be adapted to detect a variety of mutant phenotypes or to screen different chemicals on insects. Indeed, transgenesis has been achieved in several insect orders $(4,5,7,13,18)$, and it is expected that insects of economical or biomedical interest such as agricultural pests or disease vectors will soon be amenable to genetic transformation, thus opening new applications for this microplate assay.

\section{ACKNOWLEDGMENTS}

The expert technical help of Martine Schneider and Raymonde Syllas is gratefully acknowledged. We are indebted to Jean-Luc Imler for critical reading of the manuscript. We thank our colleagues for stimulating discussions. This work has been supported by institutional funds from the CNRS, grants from the French Ministère de l'Education Nationale, de la Recherche et de la Technologie (Programme de Recherche Fondamentale en Microbiologie, Maladies Infectieuses et Parasitaires). D.F. wishes to acknowledge the support of the Fondation pour la Recherche Médicale (aide à l'implantation de nouvelles équipes).

\section{REFERENCES}

1.Adams, M.D., S.E. Celniker, R.A. Holt, C.A. Evans, J.D. Gocayne, P.G. Amanatides, S.E. Scherer et al. 2000. The genome sequence of Drosophila melanogaster. Science 287:21852195.

2.Ashburner, M. 1989. Drosophila: A Laboratory Manual. CSH Laboratory Press, Cold Spring Harbor, NY.

3.Bellen, H.J., C.J. O'Kane, C. Wilson, U. Grossniklaus, R.K. Pearson, and W.J. Gehring. 1989. P-element-mediated enhancer detection: a versatile method to study development in Drosophila. Genes Dev. 3:1288-1300.

4.Berghammer, A.J., M. Klingler, and E.A.

Wimmer. 1999. A universal marker for transgenic insects. Nature 402:370-371.

5.Catteruccia, F., T. Nolan, T.G. Loukeris, C. Blass, C. Savakis, F.C. Kafatos, and A. Crisanti. 2000. Stable germline transformation of the malaria mosquito Anopheles stephensi. Nature 405:959-962.

6.Chalfie, M., Y. Tu, G. Euskirchen, W.W. Ward, and D.C. Prasher. 1994. Green fluo- rescent protein as a marker for gene expression. Science 263:802-805.

7.Coates, C.J., N. Jasinskiene, L. Miyashiro, and A.A. James. 1998. Mariner transposition and transformation of the yellow fever mosquito, Aedes aegypti. Proc. Natl. Acad. Sci. USA 95:3748-3751.

8.DeRisi, J.L., R.L. Vishwanath, and P.O. Brown. 1997. Exploring the metabolic and genetic control of gene expression on a genomic scale. Science 278:680-686.

9.Dunham, I., N. Shimizu, B.A. Roe, S. Chissoe, A.R. Hunt, J.E. Collins, R. Bruskiewich, D.M. Beare et al. 1999. The DNA sequence of human chromosome 22. Nature 402:489-495.

10.Ferrandon, D., A.C. Jung, M.C. Criqui, B. Lemaitre, S. Uttenweiler-Joseph, L. Michaut, J.M. Reichhart, and J.A. Hoffmann. 1998. A drosomycin-GFP reporter transgene reveals a local immune response in Drosophila that is not dependent on the Toll pathway. EMBO J. 17:1217-1227.

11.Hoffmann, J.A., F.C. Kafatos, C.A. Janeway, and R.A. Ezekowitz. 1999. Phylogenetic perspectives in innate immunity. Science 284:1313-1318.

12.Hoffmann, J.A. and J.-M. Reichhart. 1997. Drosophila immunity. Trends Cell Biol. 7:309-316.

13.Jasinskiene, N., C.J. Coates, M.Q. Benedict, A.J. Cornel, C.S. Rafferty, A.A. James, and F.H. Collins. 1998. Stable transformation of the yellow fever mosquito, Aedes aegypti, with the Hermes element from the housefly. Proc. Natl. Acad. Sci. USA 95:3743-3747.

14.Kopczynski, C.C., J.N. Noordermeer, T.L. Serano, W.Y. Chen, J.D. Pendleton, S. Lew is, C.S. Goodman, and G.M. Rubin. 1998. A high throughput screen to identify secreted and transmembrane proteins involved in Drosophila embryogenesis. Proc. Natl. Acad. Sci. USA 95:9973-9978.

15.Lemaitre, B., E. Kromer-Metzger, L. Michaut, E. Nicolas, M. Meister, P. Georgel, J.M. Reichhart, and J.A. Hoffmann. 1995. A recessive mutation, immune deficiency (imd), defines two distinct control pathways in the Drosophila host defence. Proc. Natl. Acad. Sci. USA 92:9465-9469.

16.Lemaitre, B., E. Nicolas, L. Michaut, J.M. Reichhart, and J.A. Hoffmann. 1996. The dorsoventral regulatory gene cassette spätzle/ Toll/cactus controls the potent antifungal response in Drosophila adults. Cell 86:973-983.

17.Little, P. 1999. The book of genes. Nature 402:467-468

18.Lobo, N., X. Li, and M.J. Fraser, Jr. 1999. Transposition of the piggyBac element in em bryos of Drosophila melanogaster, Aedes aegypti and Trichoplusia ni. Mol. Gen. Genet. 261:803-810.

19.Miklos, G.L. and G.M. Rubin. 1996. The role of the genome project in determining gene function: insights from model organisms. Cell 86:521-529.

20.Nüsslein-Volhard, C., E. Wieschaus, and H. Kluding. 1984. Mutations affecting the pattern of the larval cuticle in Drosophila melanogaster. Roux's Arch. Dev. Biol. 193:267-282.

21. Reichhart, J.M., M. Meister, J.L. Dimarcq, D. Zachary, D. Hoffmann, C. Ruiz, G.
Richards, and J.A. Hoffmann. 1992. Insect immunity-developmental and inducible activity of the Drosophila diptericin promoter. EMBO J. 1 1:1469-1477.

22.Ross-Macdonald, P., P.S. Coelho, T. Roemer, S. Agarwal, A. Kumar, R. Jansen, K.H. Cheung, A. Sheehan et al. 1999. Largescale analysis of the yeast genome by transposon tagging and gene disruption. Nature 402:413-418.

23.Rutschmann, S., A.C. Jung, C. Hetru, J.-M Reichhart, J.A. Hoffmann, and D. Ferrandon. 2000. The Rel protein DIF mediates the antifungal, but not the antibacterial, response in Drosophila. Immunity 12:569-580.

24.Rutschmann, S., A.C. Jung, Z. Rui, N. Silverman, J.A. Hoffmann, and D. Ferrandon. 2000. Role of Drosophila IK KY in a Toll-independent antibacterial immune response. Nat. Immunol. 1:342-347.

25.Sawin, K.E. and P. Nurse. 1996. Identification of fission yeast nuclear markers using a random polypeptide fusions with green fluorescent protein. Proc. Natl. Acad. Sci. USA 94:15146-15151.

26.Schena, M., D. Shalon, R.W. Davis, and P.O. Brown. 1995. Quantitative monitoring of gene expression patterns with a complementary DNA microarray. Science 270:467-470.

27.The $\boldsymbol{C}$. elegans Sequencing Consortium. 1998. Genome sequence of the nematode $C$. elegans: a platform for investigating biology Science 282:2012-2018.

28. Timmons, L., J. Becker, P. Barthmaier, C. Fyrberg, A. Shearn, and E. Fyrberg. 1997. Green fluorescent protein/ $\beta$-galactosidase double reporters for visualizing Drosophila gene expression patterns. Dev. Genet. 20:338-347.

29. Whitmarsh, A.J. and R.J. Davis. 2000. A central control for cell growth. Nature 403:255-256.

Received 29 March 2000; accepted 22 September 2000.

\section{Address correspondence to:}

Dr. Dominique Ferrandon

Institut de Biologie Moléculaire et Cellulaire

UPR 9022 du Centre

National de la Recherche Scientifique

15 Rue René Descartes

F. 67084 Strasbourg Cedex, France

e-mail:d.ferrandon@ibmc.u-strasbg.fr 